\title{
Advancing a Five-Stage Typology of Homelessness Prevention
}

\author{
Suzanne Fitzpatrick 1 | Peter Mackie 2 | Jenny Wood 1
}

1 Institute of Social Policy, Housing and Equalities Research (I-SPHERE),

Heriot-Watt University, Edinburgh, UK;

2 School of Geography and Planning,

Cardiff University, Cardiff, UK

Corresponding Author: Suzanne Fitzpatrick

Email: s.fitzpatrick@hw.ac.uk

All content published in $\mathrm{IJOH}$ is licensed under a Creative Commons Attribution-

NonCommercial-ShareAlike 4.0

International license (CC BY-NC-SA 4.0).

Received: 16 Nov 2020

Accepted: 20 Sept 2021

\begin{abstract}
This paper seeks to demonstrate the efficacy of a five-stage, temporallydriven homelessness prevention typology encompassing universal, upstream, crisis, emergency, and repeat categories. We argue that this typology can be deployed to illuminate key comparisons in homelessness prevention policy and practice between different jurisdictions and over time, while avoiding the confusions, overlaps, and ambiguities that occur in extant classifications. Drawing on an international evidence review, alongside data from a decade-long empirical study in the UK, four key lessons emerge, which we contend have resonance across much of the global north. First, though there is growing evidence of the importance of both universal prevention measures (particularly the delivery of affordable housing and poverty reduction), and upstream preventative interventions (focused on high-risk groups and transitions), practical action on both fronts has been deeply deficient to date. Second, and more encouragingly, there is a nascent shift in homelessness practice from an overwhelming focus on basic, emergency interventions, towards earlier stage attempts to avert the kind of crises that can lead to homelessness arising in the first place. Third, and also welcome, is a trend within repeat preventative interventions from treatment-led to more housing-led models, albeit that this shift has been frustratingly slow to materialise in many countries, including the UK. Fourth, there remain substantial evidence gaps across all of these categories of homelessness prevention, especially outside of the US.
\end{abstract}

\section{Keywords}

homelessness; prevention; typology; UK; US; Europe; Australia; public health

\section{Introduction}

"There has been a paradigm shift in homelessness policy-making in the developed world: we have entered an era of homelessness prevention" (Mackie, 2015: p.40). 
Preventative public policy has its roots in advances in public health, wherein it has long been accepted that the prevention of disease is better than any cure (Baumann \& Karel, n.d; Cairney, 2015). Within homelessness policy across the global north, a 'prevention turn' can readily be discerned in recent years (Mackie, 2015), underpinned by goals including cash and/or economic cost savings to the public sector (Culhane et al., 2011), overcoming government embarrassment about large numbers of homeless households on the streets or in temporary accommodation (BuschGeertsema \& Fitzpatrick 2008), and enhancing the welfare of the individuals and families directly affected (Burt et al., 2007; Crane et al., 2006; Mackie, 2015). Prevention can take the form of structural intervention and/or individual programme response (Busch-Geertsema \& Fitzpatrick, 2008). It may be targeted at whole populations, specific demographics, or a combination of the two (Shinn \& Cohen, 2019).

The various purposes, scales, contexts and issues implicated in homelessness prevention have precipitated multiple categorisations for understanding and enacting it. Such organising classifications, or typologies, are essential heuristic tools for systematic analysis and transparent comparison in the homelessness field, especially at the international level (Busch-Geertsema et al., 2016; Gaetz \& Dej, 2017; Mackie, 2015). The most commonly cited homelessness prevention typology stems from the public health field and sets out three broad tiers - primary, secondary and tertiary (Culhane et al., 2011; Montgomery et al., 2013). However, in this paper, we advance a finer-grained classification of prevention efforts which, we contend, provides a more nuanced, comprehensive, and intuitively efficacious approach.

Nowhere has the prevention turn on homelessness been more apparent than in the United Kingdom (UK) where, over the course of the last decade and longer, there have been major initiatives to re-orient homelessness policies and law in a more preventative direction (Mackie, 2015). As homelessness is a fully devolved policy area, this preventive turn has taken different forms and commenced at different points in each of the four UK jurisdictions (Fitzpatrick \& Davies, 2021). Similarities are greatest between England and Wales, where recent legislation in both countries has introduced enhanced, and very similar, homelessness prevention and relief duties. In
Scotland, a stronger statutory safety net pertains for single homeless people than elsewhere in the UK (Mackie \& Thomas, 2014), but there has been slower progress on implementing preventative interventions (Fitzpatrick et al., 2019a). Northern Ireland has tended to lag yet further behind in this regard (Fitzpatrick et al., 2020a). This diversity of approach and timing provides 'natural experiment' conditions enabling investigation of the relative effectiveness of specific aspects of homelessness prevention across the four UK jurisdictions, with a view to lesson learning not just within the UK, but in other global north countries too.

This article seeks to demonstrate the international efficacy of a five-stage homelessness prevention typology, already deployed to explore and assess policy and practice in the UK, arguing that it can be used to illuminate key comparisons between different jurisdictions on a broader scale. After reviewing existing homelessness prevention typologies, and setting out our reasoning for settling on this classification, we summarise the methods used to generate the (UK-based) empirical data drawn upon to substantiate our argument. The remainder of the paper explicates each of the five discrete categories in our favoured typology via a narrative review of relevant international literature, accompanied by its practical application via our analysis of the UK case.

\section{Assessing Homelessness Prevention Typologies}

The public health-inspired classification of homelessness prevention comprises three broad tiers: primary prevention, sometimes defined as seeking to prevent people from becoming homeless in the first place; secondary prevention, which often focuses on those at imminent risk of homelessness; and tertiary prevention, which addresses the housing and support needs of people that have already faced homelessness in an effort to prevent recurrence (Apicello, 2010; Busch-Geertsema \& Fitzpatrick, 2008).

While a helpful starting point, analogous to the 'upstream/ midstream / downstream' tripartite model used in wider public policy (Coote, 2012), this tripartite typology has courted a degree of confusion, with all three tiers defined in divergent ways. For a start, primary prevention is sometimes taken not to mean all and any efforts to obviate firsttime homelessness, but rather more precisely 'universal' interventions that reduce homelessness 
risks at the general population level (Apicello, 2010; Busch-Geertsema \& Fitzpatrick, 2008). For example, tax and welfare measures that act to reduce child poverty - demonstrated to be strongest predictor of homelessness in young adulthood in the UK (Bramley \& Fitzpatrick, 2018) - can be considered a form of primary homelessness prevention. So too can affordable housing supply and healthcare policies that increase accessibility (Shinn et al., 2013). A rather different interpretation of primary prevention focuses not (just) on universal measures aimed at the population at large, but instead on (or as well) 'upstream' measures targeting specific vulnerable individuals at an early stage in their life course. This could be via education, child protection, health care, or criminal justice policies that may reduce their risks of homelessness later in life (Shinn et al., 2001).

Secondary prevention has also been interpreted in ways that depart from that indicated above. Some authors such as Gaetz and Dej (2017), include assistance not only to those at imminent risk of homelessness but also to those who have recently become homeless to help them move on as quickly as possible. Thus, while United States (US) authors often include 'Rapid Rehousing' measures, aimed at securing sustainable accommodation for already homeless households, in their interpretation of secondary prevention (Culhane et al., 2011; Montgomery et al., 2013), European authors usually do not (for example, Busch-Geertsema \& Fitzpatrick, 2008).

Tertiary prevention is generally understood as referring to a range of support programmes to address the support needs of people experiencing repeat or chronic homelessness such as physical and/or mental ill-health and substance misuse (Apicello, 2010; Busch-Geertsema 2014; Mackie et al., 2017). However, the distinction between secondary and tertiary prevention is not entirely clear, not least as both can be interpreted as encompassing people who are currently and formerly homeless.

Shinn et al. (2001) offer an alternative tripartite approach to 'primary' prevention (by which they mean any efforts to avoid homelessness occurring in the first place), disaggregated into 'universal', 'selected', and 'indicated' homelessness prevention. Universal prevention programmes are whole population measures, while selected prevention is aimed at groups deemed to be at particular risk of homelessness, such as people exiting institutions, and indicated programmes are directed at individuals who have been deemed to be at risk through individual screening. While this population-focused typology, drawn mainly from the mental health sector (Apicello, 2010), has the benefit of internal logic and consistency, it does not incorporate a sense of the imminence of homelessness risk. We would argue that this lack of a temporal standpoint is a key weakness in this typology, as the timing of the homelessness risk its immediacy or otherwise - can imply very different practical interventions to obviate it.

A more recent attempt to categorise homelessness prevention has emerged from Canada (see Gaetz \& Dej, 2017), and was subsequently adopted in Wales to explore youth homelessness prevention (Schwan et al., 2018). These authors offer two interlinked classifications. The first is described as an 'adapted public health model' framework, which incorporates the traditional tripartite primary, secondary, tertiary distinction but, following Shinn et al. (2001), subdivides the primary stage into populationdifferentiated universal, selected, and indicated elements. The second, five-fold classification is described as a 'typology of homelessness prevention' and includes 'structural prevention', 'systems prevention', 'early intervention', 'eviction prevention', and 'housing stability'. Each of these five categories is also said to have implications for primary, secondary, tertiary prevention. This leads to a complex matrix-type classificatory scheme (though not presented as such) which is challenging to comprehend or implement.

The typology advocated by Gaetz and Dej (2017) also presents some seemingly arbitrary distinctions and conflations. For example, their 'systems prevention' unhelpfully, to our mind, separates out leaving state-run institutions from other forms of identifiable upstream risks, while aspects of structural prevention are awkwardly split between 'universal-structural' (e.g., antidiscrimination measures to address racism and homophobia) and selected-structural (e.g., reparations for Indigenous communities) subcategories. The lack of apparent logical differentiation between their first two main categories is manifest in the very similar (yet somewhat opaque) language used to describe them, with 'structural prevention' defined as pertaining to 'systemic factors that contribute to housing precarity and expose individuals and families to the risk of 
homelessness'(p.44), while 'systems prevention' is focused on 'addressing institutional and systems failures that either indirectly or directly contribute to the risk of homelessness' (p.44). The early intervention category focuses on the urgent needs of those at imminent risk of homelessness, or those who have recently experienced homelessness, rather than the longer-term planning that the term 'early' implies. Gaetz \& Dej (2017) offer a discrete 'eviction prevention' category, even though this is also described as a type of early intervention and housing stability. It is consequently unclear why it needs a separate category of its own.

Existing homelessness prevention typologies in the international literature therefore seem to veer between the excessively basic (courting ambiguity and leaving too many questions unanswered) to the bewilderingly complex (leaving readers disoriented by competing concepts and organising frameworks). Nonetheless, the core tension is clearly between population-based and temporallydriven typologies. While Apicello (2010) and Shinn et al. (2001) opt for the former, and in so doing, lose the crucial temporal dimension, Gaetz and Dej (2017) attempt to weld them together, resulting in a labyrinthian conceptual tangle. We argue that a different approach is both possible and preferable, giving primacy to the temporal targeting of interventions while accommodating key dimensions of population targeting without sacrificing logical coherence or comprehensibility.

In this spirit, we commend a five-stage homelessness prevention typology, originally coproduced by voluntary and statutory sector stakeholders in England (Business in the Community, 2019; Fitzpatrick et al., 2019b; St Basils, 2015). The core stages of this typology are as follows:

Universal - preventing or minimising homelessness risks across the population at large.

Upstream - early-stage prevention focussed on high-risk groups, such as vulnerable young people and risky transitions, such as leaving local authority care, prison, or mental health in-patient treatment.

Crisis - preventing homelessness likely to occur within a foreseeable period.

Emergency - support for those at immediate risk of homelessness, especially rough sleeping;

Repeat - prevention of recurrent homelessness, especially rough sleeping.

While the first category above (universal) may not seem at first glance a good fit in a temporally- driven hierarchy, in fact, this can be viewed as a 'pre' identifiable risk stage, as discussed further below. Upstream efforts are orientated at the earliest possible stage of assistance to identifiable at-risk population groups. The vital distinction between proximate interventions which require a short-term (crisis) response within the next several days or weeks, versus those which require an immediate (emergency) response that very day, is recognised in this time-based typology. Just as importantly, obviating risks of recurrence amongst those who have previously been homeless (repeat) is given a distinctive place in this prevention schema.

By offering discrete (mutually exclusive) categories of prevention, we argue that this classification allows for finer-grained and more systematic assessment of interventions than the earlier, more basic typologies reviewed above. At the same time, it avoids the complex hierarchies, duplication, and uncertain logic of the later, more ambitious models. The discrete compartmentalisation it offers is indispensable for a typology designed to provide a transparent and logical heuristic device for policymakers and practitioners to systematically self-assess whether they have 'all relevant bases' covered and to identify where there are gaps or imbalances in the resources expended across the relevant dimensions. This is linked to the important, if often implied, normative component of temporally-focussed typologies - i.e. that there are strong moral grounds for concentrating as much effort as possible on the earliest stage (universal and upstream) interventions, rather than relying on later stage (crisis, emergency and repeat) interventions, to avoid people experiencing the trauma and disruption associated with the threat as well as the experience of homelessness.

This typology has quickly gained traction with statutory and voluntary sector stakeholders in the UK (Fitzpatrick et al., 2020b). For example, it formed the conceptual basis of a series of reports from a Ministerial Group in Wales charged with 'recommending actions to end homelessness' (Homelessness Action Group, 2020). It similarly supplied the intellectual underpinning of a prevention-focused review established by the national homelessness charity Crisis at the request of the Scottish Government (Reid, 2021). However, it has yet to be tested with a broader global audience. Our intention with this paper is to draw 
on international literature to demonstrate the potential scope for that wider applicability and provide a more detailed treatment of the UK case by way of exemplar.

\section{Methods}

There are two key evidential components in this paper. First, we undertook a wide-ranging literature review. The initial search strategy was very broad and sought to identify works with 'homelessness' and 'prevention' in the title or keywords. The resultant papers provided an overview of the prevention landscape and helped to identify particular prevention interventions and approaches that were the focus of a further stage of more targeted searches. We also made use of the evidence and gap maps published by the Centre for Homelessness Impact - these maps are produced from systematic reviews of the largely quantitative evidence base. The review was limited to publications written in English and primarily identified studies in the global north where efforts to address homelessness prevention have been gaining traction in recent years, especially in the US, Canada, Australia, and north-western Europe.

Second, the empirical element of the paper draws on an ongoing fifteen-year, multi-method study of the homelessness impacts of economic and policy change in all four UK countries (2011-2026). This project is funded by UK homelessness charity Crisis and referred to as The Homelessness Monitor. A core element of this longitudinal study is an annual online survey of local authority homelessness service managers in England, and in alternate years in Wales and Scotland. These surveys provide considerable scope for open text responses from local authority respondents, thus generating a rich qualitative as well as quantitative dataset, broadly representative of the national picture in each country. Each year we select a particular topic to subject to 'deep dive' analysis, and in 2018-2019, the focus was on homelessness prevention in the English and Scottish surveys, having had a similar theme in the Welsh survey in 2017. Response rates of $51 \%$ were achieved in

1 Constitutional arrangements are different in Northern Ireland and local authorities do not have prime responsibility for responding to homelessness, as they do in
England ( $\mathrm{n}=166$ local authorities), 91\% in Scotland $(n=29)$, and $86 \%$ in Wales $(n=19)^{1}$.

We also undertake annual, in-depth interviews with senior stakeholders from the statutory, voluntary and independent sectors, selected to have complimentary specialist knowledge in the fields of youth, single and family homelessness, as well as offering a balance in terms of sectoral perspective and geographical location. These expert key informant interviews are audio-recorded, with informed consent, and fully transcribed before being thematically analysed. In this paper, we draw on testimony from interviews conducted in England in 2019 and Scotland in late 2018, supplemented by additional prevention-focussed interviews conducted in Northern Ireland and in Wales in 2019, supported by the UK Collaborative Centre for Housing Evidence (CaCHE) as part of its core 'Homelessness' research theme ${ }^{2}$. This amounts to a total of 35 transcripts: 14 in England; eight in Scotland; seven in Wales; and seven in Northern Ireland. The balance between statutory and voluntary sector key informants was 15 and 18 respectively, with an additional two interviewees providing national overviews from an 'independent' perspective.

We will now interrogate each of the five stages of the typology from an international perspective, before deploying this classification to assess and compare the relative effectiveness of prevention efforts in the UK jurisdictions.

\section{Universal Prevention}

There has been a recent growth in international scholarly efforts to demonstrate the importance and impacts of universal prevention efforts that seek to reduce homelessness risks at the general population level (see Apicello, 2010; Johnson et al., 2019; O'Donnell, 2019). A wide range of society-wide conditions might plausibly be argued to shape population-wide risks of homelessness, including overall levels of violence (especially domestic and family violence) (Parsell \& Fitzpatrick, 2016), access to affordable healthcare (Shinn et al., 2013) and childcare (Gaetz \& Dej, 2017), the protections available at the lower end of the labour market 
(Stephens et al., 2010), and regional disparities in economic performance (Fitzpatrick et al., 2021a). However, across the global north, two key areas of universal intervention emerge as paramount; first, social welfare policy and wider efforts to reduce poverty; and second, delivery of sufficient affordable housing. In their international review of youth homelessness literature, for example, Schwan et al. (2018, p. 12) postulate that countries with "robust welfare states and embedded poverty reduction strategies report lower rates of child poverty and homelessness". Scandinavian countries with social democratic welfare regimes, therefore, perform well in relation to universal prevention of homelessness (Olsson \& Nordfeldt, 2008), exhibiting homelessness rates (or at least use of homelessness services) that are considerably below countries with less protective welfare systems, notably the US (Benjaminsen, 2015; Benjaminsen \& Andrade, 2015; see also Stephens et al. (2010)). This persists even though austerity-associated reductions in social security protection in the last decade have impacted much of Europe (Heise \& Lierse, 2011).

Affordable housing supply is frequently cited as a cornerstone of effective universal homelessness prevention (Johnson et al., 2019; O’Donnelly, 2019), with area-level studies in the US consistently finding that the volume of homelessness is determined largely by housing market conditions, particularly rent levels and vacancy rates (Quigley et al., 2001). In two separate Australian studies, public housing proved to be a strong protective factor against homelessness (Johnson et al, 2019; O'Donnelly, 2019; see also O'Flaherty, 2004), and countries with apparently low rates of homelessness, such as Finland and Denmark, have invested heavily in affordable housing (O'Sullivan, 2020; Schwan et al., 2018). However, social housing construction is in decline across much of the global north (Johnson et al., 2019).

Moving on to the UK specifically, statistical modelling has found that "the most important driver of homelessness in all its forms is poverty' with another key structural driver the 'availability and affordability of accommodation" (Bramley, 2017, p.14). Significant reductions in social security protection since the Coalition Government took office in 2010 (Vizard \& Hills, 2021), coupled with acute and worsening affordable housing shortages (Stephens et al., 2020), means that the UK's recent record on universal homelessness prevention is poor (Fitzpatrick et al., 2017; 2019a, c; 2020a). Homelessness levels have risen particularly sharply in England, where housing affordability strains, and the impact of reductions in help with housing costs for lowincome tenants, cut deepest. Conversely, lower housing market pressures, higher levels of investment in social housing (especially in Scotland), and welfare reform mitigation measures undertaken by the devolved administrations, mean that patterns are more variable in other UK jurisdictions.

Figure 1 demonstrates that, in 2010, England and Scotland had similar levels of 'core homelessness' - denoting the more 'extreme' forms of homelessness, such as rough sleeping and highly unsuitable temporary accommodation. Since then, however, English levels of core homelessness have risen, Scottish levels have declined, and Wales has exhibited a consistently lower rate than both. 


\section{Figure 1}

'Core' homelessness per 1,000 households by country, 2010-17

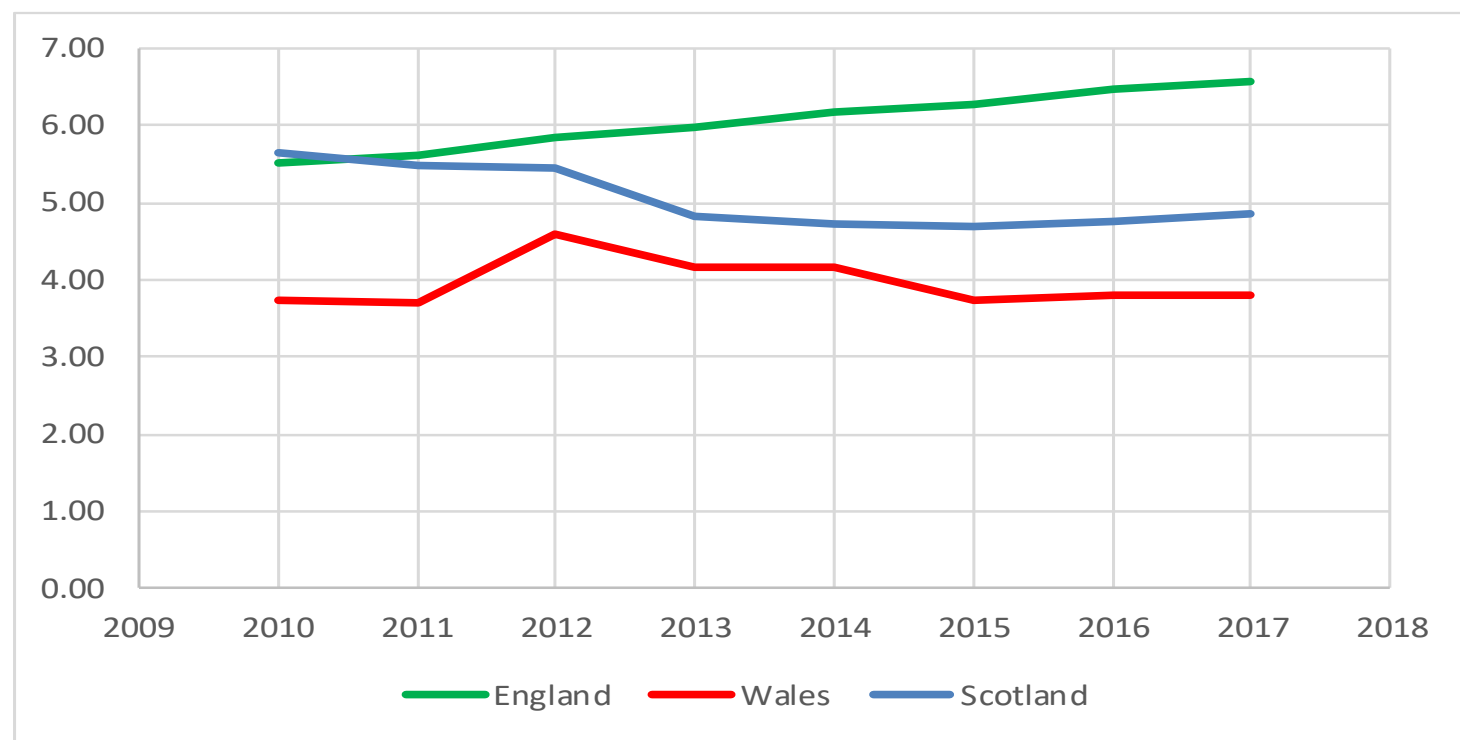

Source: Fitzpatrick \& Bramley (2021)

These statistical trends are consistent with testimony from senior stakeholders and local authority representatives. In all four UK jurisdictions welfare cuts and housing shortages were perceived to be implicated in homelessness pressures, but the earliest and most profound effects were said to be found in London and the South of England. Severe cuts in 'Local Housing Allowance' (LHA) (the form of housing subsidy made available to low-income private sector tenants in the UK) were viewed as especially damaging, especially after a four-year cash 'freeze' which meant that maximum LHA rates failed to keep pace with rising rent levels:

"...the LHA freeze has been a huge factor in the increase in homelessness, pushing families into a position where they cannot afford the private sector" (England, Statutory Sector).

"... whole benefit level freeze again is a huge concern for us... the Local Housing Allowance rates... The cost of rent and the gap between that and people's income is just pushing more people into a place where they're at risk of becoming homeless." (England, Voluntary Sector)

\section{Upstream Prevention}

Despite an evidence base demonstrating that some groups are at much higher risk of homelessness, efforts to prevent their homelessness have been underwhelming and traditionally dogged by difficulties in accurately predicting who would become homeless absent of intervention (Apicello, 2010). Nonetheless, recent studies suggest that improved data gathering and sharing can aid better predictive decision-making (Gaetz \& Dej, 2017; Thomas \& Mackie, 2020), and there is a growing practice and literature, mostly from the US, which uses statistical modelling and forms of machine learning to identify individuals at particular risk (Pleace, 2019; see also Greer et al., 2016; Hudson \& Vissing, 2010; Kube et al., 2019; Shinn et al., 2013).

A very different model of upstream homelessness prevention is captured in the "The Geelong Project' approach, which emerged originally from Australia, and uses a screening survey conducted with all children in school settings in Geelong to identify those at risk of homelessness. Children and their families are subsequently supported to address conflict and concerns at home, and in the early stages of this intervention, youth homelessness was reportedly reduced by approximately 40\% (Mackenzie, 2018).

One area where predictions of homelessness are very often borne out relates to those leaving state institutions, especially the criminal justice system (Spencer \& Jones-Walker, 2004; Todis et al., 2001) and state care of children (Johnson \& Mendes, 
2014; Schwan et al., 2018), but also healthcare settings (Cornes et al., 2019) and the armed forces (Wilding, 2020). The best-evidenced prevention approach to minimising post-institutional homelessness is Critical Time Interventions (CTIs) (Kasprow \& Rosenheck, 2007; Lutze et al., 2014), which Herman et al. (2007: 296) define as "an individual-level intervention designed to reduce the risk of homelessness and other adverse outcomes following discharge from institutions to community living." CTIs typically last nine months, with a case manager offering continuity of care from within an institutional setting to community-based support (Hignite \& Haff, 2017), and an emphasis on rebuilding supportive social networks (Herman et al., 2007).

In the UK early intervention efforts remain weak. This is despite a firm understanding that leaving a state institution too often results in homelessness (Mackie \& Thomas, 2014), coupled with a growing policy interest in 'predictive analytics' that enables the identification of 'at-risk' groups (Alma Economics, 2019; Bramley \& Fitzpatrick, 2018):

"...there [is] lots we can do earlier in people's lives and again that goes back to ... agencies working together well earlier to help prevent those problems further down the line in people's lives." (England, Voluntary Sector)

There is, for example, little deployment of CTI methods, and only one pilot intervention in Wales of the whole community approach captured in The Geelong Project ${ }^{3}$. That said, there are efforts being made to promote sustainable accommodation on release for prisoners in Scotland, and improvements in support for children leaving state care are apparent in many parts of the UK (Stirling, 2018; Watts et al., 2015). Moreover, social landlords often do a creditable job in preventing high-risk tenants from reaching crisis (Watts et al., 2019), as was noted by this senior key informant in Wales:

"...there's some good stuff going on in social housing around identification... to try and keep people in their homes... around preventing people from getting to eviction stage because of their

3

https://www.endyouthhomelessness.cymru/voices/upst ream-cymru-update behaviour, looking at working with households in a different way and with the community, seeing those issues as part of something bigger and what can we do to help families." (Wales, Voluntary Sector)

Yet, public sector funding cuts over the past decade have tended to draw energy away from upstream prevention efforts towards more crisisfocused interventions (Thunder \& Rose, 2019):

“...it's very, very hard to take that really bold decision that actually, we should invest upstream, because what do you do with all the people who are already downstream? ... you would need a bit of additional money, even to facilitate that shift, because there's so many people already down here; you can't take the money away from them." (Northern Ireland, Voluntary Sector)

"I don't think we've really got into talking enough about upstream and predictive modelling and things like that. Simply because of firefighting...[because] of the external policy environment, welfare reform and lack of supply, and government cuts... I think it's very hard to show the benefits of the upstream stuff when you've constantly - you've got so many thousands of people in temporary accommodation..." (England, Statutory Sector)

Another concern is that misdirected efforts with intuitive appeal can waste what little resource is focused on targeted upstream prevention. For example, generic homelessness education provided as part of the school curriculum is a popular intervention in the UK (see Scottish Parliament Equal Opportunities Committee, 2012), but there is little evidence to support its effectiveness (Watts et al., 2015):

“...if you've a limited amount of money...is educating primary school children about [homelessness]...the best way to spend it? ...would you not be better targeting it at youth clubs in deprived areas." (Northern Ireland, Voluntary Sector)

The failure to engage a sufficiently wide range of public bodies in homelessness prevention efforts is a key limitation on upstream interventions, given evidence that the education, health, and criminal

86 | International Journal on Homelessness: https:/ /ijoh.ca

https://www.sps.gov.uk/Corporate/Publications/Public ation-5363.aspx 
justice sectors often come in contact with high-risk groups at a much earlier point than housing and homelessness services (Fitzpatrick et al., 2013). While the Homelessness Reduction Act 2017 implemented new duties on a range of public bodies in England to 'refer' people at risk of homelessness to relevant local authority services, most senior key informants felt that this did not go far enough in tying these wider services into preventative solutions. There was therefore great interest in Scotland to implement a more broadranging public sector homelessness prevention duty (see Reid, 2021):

"I think the Scottish Government should move to establishing prevention of homeless duties for ...health and social care partnerships, housing associations and prisons and health boards. I don't think it's something we should shy away from and enshrining it in legislation as a statement of what Scotland wants to do in terms of prevention of homelessness." (Scotland, Statutory Sector)

\section{Crisis Prevention}

Across Europe, the US and Australia, an array of interventions centre on households at high risk of homelessness in the relatively near future. Evictions prevention tends to predominate, reflecting the fact that rent arrears are the primary trigger of homelessness in many countries in the global north. Thus, in their comprehensive European review, Kenna et al. (2016) identified several countries where there are legal requirements on courts to notify local authorities when evictions proceedings are initiated and in many parts of Europe, shortterm financial assistance is available to help prevent an eviction (Kenna et al., 2016). In the US, the Homelessness Prevention and Rapid Re-housing Program (HPRP), the largest homelessness prevention programme in the country's history (Berg, 2013; Byrne et al., 2016), also had a strong focus on short-term emergency financial assistance to prevent evictions and repossessions (Piña \& Pirog, 2019; Shinn and Cohen, 2019), and there is emerging evidence of the effectiveness of these measures (Evans et al., 2016). While financial assistance predominates, other forms of crisis intervention to prevent eviction can also be identified. For example, Schwan et al. (2018) highlight the role of legal support, advice, and representation, and landlord-tenant mediation, in preventing evictions, though Shinn and Cohen (2019) observe that there are few studies of the effectiveness of these interventions.

Domestic abuse is another key trigger of homelessness globally (Spinney \& Blandy, 2011; Tutty et al., 2013), with traditional emergency responses focusing on specialist refuges for women and children fleeing such abuse (Abrahams, 2010). More recently, however, there has been growing investment in schemes to exclude the perpetrator and enable the survivor(s) to remain safely in the family home with additional security and support. There is now a small but positive evidence base that speaks to the effectiveness of these innovative 'sanctuary' models (Jones et al., 2010; Spinney \& Blandy, 2011).

As elsewhere in the global north, crisis forms of homelessness prevention have been the focus of concerted efforts in recent years in the UK, but reflecting the peculiarities of the British welfare state, they take quite a distinctive form in at least two respects. First, there has been less focus on eviction prevention than in many other countries as rent arrears have not typically dominated as an immediate trigger of homelessness to the extent they do elsewhere (Busch-Geertsema \& Fitzpatrick, 2008). This reflects the highly protective role historically played by the Housing Benefit system, whereby all of the eligible rent of low-income households in both the private and social rented sectors could be covered by this entitlement-based housing assistance programme. However, as noted above in discussions on Local Housing Allowance rates, deep cuts in Housing Benefits since 2010, especially for private sector tenants, have been associated with a massive increase in the numbers made homeless after the ending of a private tenancy in England (Fitzpatrick et al., 2019c). Nonetheless, relationship breakdown, or being asked to leave accommodation by family and friends, remain more significant triggers of 'statutory' homelessness within the UK than rent arrears (Fitzpatrick et al., 2021a).

Second, the UK's unique homelessness legislation has offered certain categories of homeless people enforceable legal rights to settled accommodation, since the coming into force of the Housing (Homeless Persons) Act 1977. This legislation has diverged in important ways between the four UK countries post-devolution (Fitzpatrick \& Davies, 2021). However, the core principle - of entitlement to long-term accommodation for 
homeless families with children and at least some categories of 'vulnerable' single homeless adults has remained. The Housing (Wales) Act 2014, and subsequently the Homelessness Reduction Act 2017 in England, were designed to address two main flaws in these longstanding legal arrangements: a lack of focus on prevention, and the exclusion of many single people from material assistance. English and Welsh local authorities now must take 'reasonable steps' to avert homelessness for those at risk within the next two months (56 days), regardless of household type or level of 'vulnerability'. Reasonable steps typically consist of support to retain existing accommodation or find suitable alternative accommodation in the social or private rented sectors, often through financial assistance such as payment of rent arrears, rent in advance, or a deposit.

An official evaluation of the revised legal framework in Wales was very positive (Ahmed et al., 2018), and the balance of opinion amongst our key informants and local authority respondents was that these changes had facilitated significant strides forward in crisis prevention in England too:

"...what's really been impressive has been the change of culture in local authorities. That is especially in the context of single people who previously would have been found not in priority need, and in many councils offered very little help." (England, Independent Sector)

"I think [The Homelessness Reduction Act is] the most progressive piece of legislation for probably 30 years at least ... the 56-day obligation to address their homelessness, that is a fundamental change, and you can see that it's having an impact." (England, Statutory Sector)

"We're definitely doing better than we were five years ago. We're definitely providing more of a wraparound service and we've definitely got a lot more options available to support people." (Wales, Statutory Sector)

As previously noted above, Scotland has a policy commitment to introduce stronger homelessness prevention legislation, modelled on the English and Welsh approaches, but incorporating duties on a wider set of public bodies (Reid, 2021). One key informant expressed enthusiasm for doing the same in Northern Ireland:

"One of the things I'm really interested in...is...whether we should have some of the preventative duties or obligations because what I get from Welsh and English authorities is it's a cultural thinking that shifts around prevention and it's statutory and we tend to do things that you get measured on, rightly or wrongly... I like the idea of the 56 days and the kind of options there and the mandatory stuff." (Northern Ireland, Statutory Sector)

\section{Emergency Prevention}

For decades homelessness assistance across the global north has centred on the emergency needs of those at immediate risk of homelessness, especially sleeping rough, with hostels and shelters the principal accommodation-based response. This type of provision is often located within a 'staircase' model, whereby homeless individuals are expected to move through different forms of communal or congregate accommodation until they are deemed 'housing ready' and allocated independent settled housing (Mackie et al., 2017). However, this staircase model results in some people being stuck for long periods in settings initially designed to fulfil an emergency and temporary role, while at the same time eviction and abandonment rates are high (Busch-Geertsema et al., 2010).

There is compelling evidence of the harmful effects these communal environments can have on vulnerable people (Keenan et al., 2020; McMordie, 2020), though there are also indications of successful longer-term housing outcomes for some of those who can manage to 'stay the course' (Crane et al., 2011). Generic hostels and shelters are frequently deemed unsuitable for particular population subgroups who might be especially vulnerable in these settings. Therefore, specialist youth accommodation projects, for example, are provided in many countries (Curry \& Petering, 2017; Gaetz 2014).

The UK record on emergency support for those at immediate risk of sleeping rough - mainly single people - is mixed and often poor. Despite the existence of a statutory homelessness safety net for over 40 years, there is no legal obligation to provide emergency accommodation to single people in England, Wales or Northern Ireland, even if they are at high risk of sleeping rough. This leaves them in a weaker (legal) position than in some other European countries where a right to emergency shelter exists (Fitzpatrick et al., 2014). The situation in Scotland is quite different, with virtually all 
homeless people having an enforceable right to temporary accommodation since 2001, though some Scottish local authorities routinely fail to fulfil this duty (Watts et al., 2018).

That said, there have been specialist targeted programmes funded to tackle rough sleeping over many years, stretching back to the first Rough Sleepers Initiative in England in the early 1990s (Mackie et al., 2017). These initiatives often demonstrate considerable success in reducing street homelessness, only for the numbers to rise again when political priorities move on. The most recent national Rough Sleeping Strategy in England, (Ministry of Housing, Communities and Local Government (MHCLG), 2018) was accompanied by a funding programme that has supported a range of new practical interventions. This includes 'Somewhere Safe to Stay' pilots, intended to rapidly assess the needs of people who are sleeping rough or at risk, and 'navigators', who are specialists employed to help coordinate access to local services for people who sleep rough. An almost decade-long strong upward trajectory in official rough sleeping figures started to reverse after the implementation of this programme (see Figure 2), with an internal evaluation finding that areas in receipt of programme funding saw disproportionate falls in street homelessness (MHCLG, 2019). As elsewhere in the global north, larger-scale hostels and communal shelters are still sometimes relied upon in emergency situations in the UK (Fitzpatrick et al., 2021a; Mackie et al., 2017), particularly for single homeless people without statutory entitlements to rehousing (temporary furnished flats in the social or private rented sectors is much more commonly used to meet the emergency and temporary accommodation needs of those assisted by local authorities in pursuit of their statutory duties (Watts et al., 2018)). Longstanding evidence that many homeless people would rather sleep rough than stay in these intimidating congregate environments (Jackson, 2018; McMordie, 2020) has been a key prompt for the development of alternative models. One example is 'host homes' schemes offering placements with private households by way of emergency and/or respite accommodation for young people at risk of exclusion from the family home (Watts et al., 2015).

\section{Repeat Prevention}

Repeat prevention intervenes when homelessness has already occurred, and the goal is to avoid recurrent episodes. Much of the contemporary repeat prevention discourse focuses on Rapid Rehousing and Housing First approaches, which mark a departure from the traditional

\section{Figure 2}

Trends in local authority rough sleeper estimates by broad region, 2004-2019

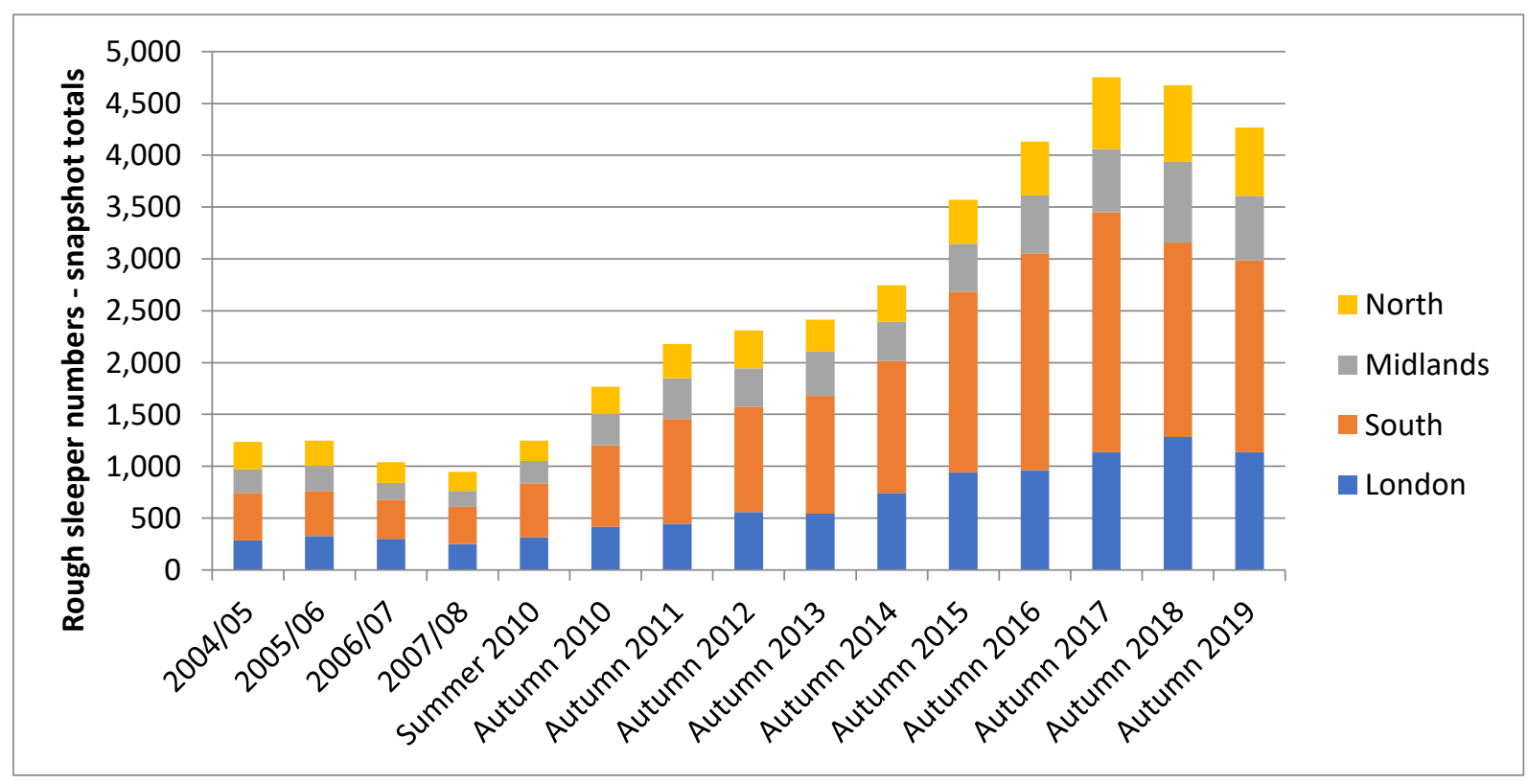

Source: MHCLG official statistics

89 | International Journal on Homelessness: https://ijoh.ca 
staircase model because they are housing-led and focus "on helping people into permanent accommodation before addressing any other issues they may need support with" (Downie et al., 2018, p. 134).

Whilst research on Rapid Rehousing is sparse, Cunningham et al. (2015) found that this approach - generally targeted at homeless people with relatively low support needs - is successful at enabling households in the US to exit homelessness swiftly, with low rates of initial returns to hostels or shelters. However, Rapid Rehousing does not in and of itself solve longer-term affordability challenges, with many formerly homeless households in the US suffering ongoing residential instability unless they can access appropriate rental subsidies.

Housing First is, by some distance, the most researched form of homelessness intervention, and is generally judged to be an effective response for households with higher and more complex support needs (Woodhall-Melnik \& Dunn, 2016), in large part because of its consistently positive results on tenancy sustainment (Mackie et al., 2017). These programmes provide permanent housing alongside person-centred support that is available for as long as a person needs it. Importantly, there are no preconditions on participation in treatment programmes (Aubry et al., 2015; Pearson et al., 2009; Tsemberis, 2010). Housing First began in the US and has subsequently been implemented, with varying degrees of fidelity, in Australia (Kertesz \& Johnson, 2017), Canada (Aubry et al., 2015) and Europe (Busch-Geertsema, 2014; Pleace et al., 2016).

The effectiveness of efforts to prevent the recurrence of homelessness has varied both within and between UK countries over time. Currently, Wales and Northern Ireland are in a much better position than Scotland and, especially, England because of the protection given by their respective governments to their 'Supporting People' core revenue funding stream. This finances housingrelated support that enables vulnerable people to sustain accommodation:

"...being able to ringfence and keep Supporting People funding to date has been a huge success. Okay, we're all complaining about it shrinking or at least about it staying still, but it is a success in homelessness policy in Northern Ireland that Supporting People still exists. That money hasn't been subsumed in the local government, and most importantly that it has been ringfenced so the money is still going into homelessness services." (Northern Ireland, Voluntary Sector)

In sharp contrast, this Supporting People funding has been cut by almost four-fifths in England since 2010 (Fitzpatrick et al., 2019c), fundamentally impacting on the support available to ex-homeless people:

“...you've taken $£ 2$ billion out of the supported housing budget, over the last X number of years, and the amount that's being invested through the Rough Sleeping Strategy just pales into insignificance, as a result... we're in a situation where we've damaged the wider services." (England, Voluntary Sector)

More positively, major Housing First initiatives are now underway in all three GB countries, with relevant projects established in Northern Ireland (Fitzpatrick et al., 2020a). However, as elsewhere, there are concerns about fidelity to the model, and in particular whether there are appropriate resources and commitment from health and social services to meet the complex support needs of the group targeted:

"...the big thing for me about Housing First is if you're going to do it, do it properly, resource it properly, make sure that health are engaged. I think there's then a danger if you don't do that and it doesn't work, we're in danger of discrediting I think what is a really good model." (Scotland, Voluntary Sector)

The Housing First initiatives in Scotland and England are subject to major evaluations, which will add to the already significant international evidence based on this intervention. Furthermore, in Scotland and Wales, Ministerial Action Groups (reporting in $2018^{5}$ and $2020^{6}$ respectively) called for a greater focus on Rapid Rehousing, with both governments subsequently committing to shift towards more housing-led responses, with support of key players in the statutory and voluntary sectors:

\footnotetext{
${ }^{5}$ https:/ / www.gov.scot/groups/homelessness-and-roughsleeping-action-group/
}

${ }^{6}$ https://gov.wales/homelessness-action-group 
"...we need to do more prevention of homelessness in Scotland... We also need to think about how we get people through temporary accommodation if they need to go in there in the first place... much more smartly and obviously get people sustained in accommodation. [Rapid Rehousing] also gives us an opportunity to really have some leverage where key partners like housing associations, health and social care partnerships, and other services, to get them on board with homelessness... So this is a vehicle to try and drive that culture change within local authorities and partnerships." (Scotland, Statutory Sector)

\section{Conclusion}

In this paper, we have made the case for the efficacy of a five-stage typology of homelessness prevention and its international applicability across the global north. The typology separates out population-wide (universal) from focussed (upstream) prevention, while also recognising the vital distinction between more proximate interventions which require a short-term (crisis) or an immediate (emergency) response. The prevention of recurrence (repeat) for those who have already experienced homelessness also has a place within the schema. We would argue that this temporally-driven typology allows for systematic comparison between jurisdictions and over time, and normative assessment of the balance of activities, whilst avoiding the confusion, duplication and ambiguity that occurs in other classifications.

Our application of this analytical typology to the UK case has enabled us to foreground three broad trends that we argue also resonate elsewhere in the global north. First, there is growing evidence pointing to the importance of universal prevention interventions, particularly the delivery of sufficient affordable housing and effective poverty reduction strategies. Yet, austerity-associated reductions in social security protection over the past decade in many global north countries, including the UK, coupled with an overall decline in new social housing supply, means that progress in regard to universal homelessness prevention is hard to come by. Second, and more encouragingly, we can see nascent signs that prevention practice has begun to shift earlier within the five-stage prevention typology, from emergency interventions with street homeless people (e.g., hostels, shelters, and food distribution), to crisis prevention interventions, and to a lesser extent upstream interventions, in at least some contexts. The most significant change in this regard in the UK has been new legislation in Wales and England ushering in legal duties on local authorities to take reasonable steps to prevent homelessness, with the likelihood of similar legal developments in Scotland in the near future. Third, widespread endorsement of Housing First, and to a lesser extent Rapid Rehousing, is driving a trend in repeat prevention towards more housing-led approaches, with a corresponding decline in the focus on the traditional staircase model, though this shift has been frustratingly slow to materialise 'at scale' in the UK and some other countries.

This typology-driven analysis has also laid bare the very significant evidence gaps that exist on the effectiveness of key homelessness prevention interventions, particularly outside of the US7. In the few instances where evidence is strong, for example on the importance of affordable housing supply, welfare protection, or on the effectiveness of Housing First, policy and practice implementation have often been patchy, slow or even subject to retrograde steps.

As has recently been highlighted by other scholars (Parsell et al., 2020), the COVID-19 pandemic - which occurred after the empirical research drawn upon in this paper was conducted but before the paper was completed - has precipitated a rapid reframing of street homelessness as a public health crisis, rather than a mere 'social' problem (Fitzpatrick et al., 2021b). This reframing has precipitated a much more inclusive, effective and sympathetic policy response than would have been thought possible pre-pandemic. While this newly progressive stance may be driven to at least some extent by a dispiritingly selfregarding concern that these vulnerable people's circumstances pose an infection risk to the wider population, it is nonetheless vital to grasp the opportunity that it represents. By tacking close to this health-driven agenda, we can hope to embed not only a more comprehensive and generous approach to tackling homelessness, at least in its

${ }^{7}$ https://www.homelessnessimpact.org/gap-maps 
most extreme manifestations, we can also take inspiration from the public health model in seeking to lift our ambition from crisis management to preventative approaches that genuinely seek to avoid homelessness occurring in the first place. We hope that the proposed five-stage homelessness prevention typology advanced here offers a helpful heuristic tool for tracking progress (and regress), in this endeavour in years ahead, as the world seeks to 'build back fairer' after the profound health, economic and social shocks precipitated by the COVID-19 catastrophe.

\section{Acknowledgements}

The authors gratefully acknowledge the support of the ESRC, AHRC and JRF via the 'UK Collaborative Centre for Housing Evidence (CaCHE)', (ES/P008852/1). This research also drew heavily on work conducted as part of the Homelessness Monitor series, funded by $\mathrm{CaCHE}$ partners Crisis and the Joseph Rowntree Foundation. We would like to acknowledge the useful input from Dr. Beth Watts, Dr. Francesca Albanese, and Professor Ken Gibb on early iterations of these ideas. In addition we extend our thanks to attendees at the Housing Studies Association annual conference 2019, and at the CaCHE Northern Ireland Knowledge Exchange Hub meeting held on 11th June 2019, for their constructive comments and suggestions. Finally, we are very grateful to the anonymous referees whose comments greatly enhanced the quality of our arguments.

\section{References}

Abrahams, H. (2010). Rebuilding lives after domestic abuse: Understanding long-term outcomes. London: Jessica Kingsley Publishers.

Ahmed, A., Wilding, M., Gibbons, A., Jones, K., Rogers, M., \& Madoc-Jones, I. (2018). Postimplementation evaluation of part 2 of the Housing (Wales) Act 2014: Final report. Cardiff: Welsh Government.

Alma Economics (2019). Homelessness: Causes of homelessness and rough sleeping. Review of models of homelessness. London: MHCLG and Department for Work and Pensions.

Apicello, J. (2010). A paradigm shift in housing and homeless services: Applying the population and high-risk framework to preventing homelessness. The Open Health Services and Policy Journal, 3, 41-52.

Aubry, T., Nelson, G., \& Tsemberis, S. (2015). Housing First for people with severe mental illness who are homeless: A review of the research and findings from the at HomeChez soi Demonstration Project. The Canadian Journal of Psychiatry, 60(11), 467474. https:// doi.org/10.1177\%2F07067437 1506001102

Baumann, L. C., \& Karel, A. (n.d.). Prevention: Primary, secondary, tertiary. In Encyclopedia of Behavioral Medicine (1532-1534). New York: Springer. https:/ / doi.org/10.1007 /978-1-4419-1005-9_135

Benjaminsen, L. (2016). Homelessness in a Scandinavian welfare state: The risk of shelter use in the Danish adult population. Urban Studies, 53(10), 2041-2063. https://doi.org/10.1177/0042098015587818

Benjaminsen, L., \& Andrade, S. B. (2015). Testing a typology of homelessness across welfare regimes: Shelter use in Denmark and the USA. Housing Studies, 30(6), 858-876. https://doi.org/10.1080/02673037.2014.982 517

Berg, S. (2013). The HEARTH Act. Cityscape, 15(1), 317-323.

Bramley, G. (2017). Homelessness projections: Core homelessness in Great Britain. London: Crisis.

Bramley, G., \& Fitzpatrick, S. (2018). Homelessness in the UK: Who is most at risk? Housing Studies, 33(1), 96-116. https://doi.org/10.1080/02673037.2017.134 4957

Burt, M. R., Pearson, C., \& Montgomery, A. E. (2007). Community-wide strategies for preventing homelessness: Recent evidence. The Journal of Primary Prevention, 28(3-4), 213-228. https://doi.org/10.1007/s10935007-0094-8

Busch-Geertsema, V. (2014). Housing First Europe - Results of a European social experimentation project. European Journal of Homelessness, 8(1), 13-28.

Busch-Geertsema, V, Edgar, W., O'Sullivan, E., \& Pleace, N. (2010). Homelessness and homeless policies in Europe: Lessons from research. Brussels: European Commission.

Busch-Geertsema, V., Culhane, D., \& Fitzpatrick, S. (2016). Developing a global framework for conceptualising and measuring 
homelessness. Habitat International, 55, 124132. https://doi.org/10.1016/j.habitatint. 2016.03.004

Busch-Geertsema, V, \& Fitzpatrick, S. (2008). Effective homelessness prevention? Explaining reductions in homelessness in Germany and England. European Journal of Homelessness, 55, 124-132. http:/ / dx.doi.org/10.1016/j.habitatint.2016.03.004

Business in the Community (2019). Designing out homelessness: Practical steps for business. London: Business in the Community.

Byrne, T., Treglia, D., Culhane, D., Kuhn, J., \& Kane, V. (2016). Predictors of homelessness among families and single adults after exit from homelessness prevention and rapid rehousing programs: Evidence from the Department of Veterans Affairs Supportive Services for Veteran Families Program. Housing Policy Debate, 26(1), 252-275. https://doi.org/10.1080/10511482.2015.106 0249

Cairney, P. (2015). Prevention is better than cure, so why isn't government policy more preventive? Political Insight, 6(3), 36-39. https://doi.org/10.1111/2041-9066.12114

Coote, A. (2012). The Wisdom of Prevention. London: New Economics Foundation.

Cornes, M., Aldridge, R., Tinelli, M., Whiteford, M., Hewett, N., Clark, M., Neale, J., Hayward, A., Bing, R., Manthorpe, J., Foster, G., Biswell, E., Menezes, D., Blackburn, R., Lewer, D., Harris, J., Fuller, J., Kilmister, A., Coombes, J., \& O'Shea, D. (2019). Transforming out-of-hospital care for people who are homeless. Support Tool $\mathcal{E}$ Briefing Notes: complementing the High Impact Change Model for transfers between hospital and home. NIHR Policy Research Unit in Health and Social Care Workforce, The Policy Institute, King's College London. https://doi.org/10.18742/pub01007

Crane, M, Warnes, T., \& Coward, S. (2011). The FOR-HOME study moves to independent living single homeless people's experiences and outcomes of resettlement. Sheffield: University of Sheffield.

Crane, M., Warnes, A. M., \& Fu, R. (2006). Developing homelessness prevention practice: Combining research evidence and professional knowledge. Health and Social
Care in the Community, 14(2), 156-166. https://doi.org/10.1111/j.13652524.2006.00607.x

Culhane, D. P., Metraux, S., \& Byrne, T. (2011). A prevention-centered approach to homelessness assistance: A paradigm shift? Housing Policy Debate, 21(2), 295-315. https://doi.org/10.1080/10511482.2010.536 246

Cunningham, M., Gillespie, S., \& Anderson, J. (2015). Rehousing: What the research says. New York: The Urban Institute.

Curry, S., \& Petering, R. (2017). Resident perspectives on life in a transitional living program for homeless young adults. Child and Adolescent Social Work Journal, 34(6), 507515. https://doi.org/10.1007/s10560-0170488-2

Downie, M., Gousy, H., Basran, J., Jacob, R., Rowe, S., Hancock, C., Albanese, F., Pritchard, R., Nightingale, K., \& Davies, T. (2018). Everybody in: How to end homelessness in Great Britain. London: Crisis.

Evans, W. N., Sullivan, J. X., \& Wallskog, M. (2016). The impact of homelessness prevention programs on homelessness. Science, 353(6300), 694-699. https:// doi.org/10.1126/science.aag0833

Fitzpatrick, S., Bengtsson, B., \& Watts, B. (2014). Rights to housing: Reviewing the terrain and exploring a way forward. Housing, Theory and Society, 31(4), 447-463. https://doi.org/10.1080/14036096.2014.923 506

Fitzpatrick, S., \& Bramley, G. (2021). The ruling parties' record on homelessness and complex needs (May 2015 to pre-COVID 2020).

LSE/CASE, Heriot-Watt University and Nuffield Foundation.

Fitzpatrick, S., Bramley, G., \& Johnsen, S. (2013). Pathways into multiple exclusion homelessness in seven UK cities. Urban Studies, 50(1), 148-168. https:// doi.org/10.1177/0042098012452329

Fitzpatrick, S., \& Davies, L. (2021). The 'ideal' homelessness law: balancing 'rights-centred' and 'professional-centred' social policy. Journal of Social Welfare \& Family Law, 43(2), 175-197. https://doi.org/10.1080/ 09649069.2021.1917712

Fitzpatrick, S., Mackie, P., Pawson, H., Watts, B., \& Wood, J. (2021b), The COVID-19 crisis 
response to homelessness in Great Britain: Interim report. Glasgow: UK Collaborative Centre for Housing Evidence.

Fitzpatrick, S., Mackie, P. and Wood, J. (2019b) Homelessness Prevention in the UK: Policy Briefing. Glasgow: UK Collaborative Centre for Housing Evidence

Fitzpatrick, S., Mackie, P. and Wood, J. (2020b) Homelessness Prevention in the UK: Emerging Impact of $\mathrm{CaCHE}$ Analysis. Glasgow: UK Collaborative Centre for Housing Evidence Fitzpatrick, S., Pawson, H., Bramley, G., Watts, B., Wood, J., Stephens, M., \& Blenkinsopp, J. (2019a). The Homelessness Monitor: Scotland 2019. London: Crisis.

Fitzpatrick, S., Pawson, H., Bramley, G., Wood, J., Stephens, M., Frey, J., \& McMordie, L. (2020a). The Homelessness Monitor: Northern Ireland 2020. London: Crisis.

Fitzpatrick, S., Pawson, H., Bramley, G., Wilcox, S., Watts, B., \& Wood, J. (2017). The

Homelessness Monitor: Wales 2017. London: Crisis.

Fitzpatrick, S., Pawson, H., Bramley, G., Wood, J., Watts, B., Stephens, M., \& Blenkinsopp, J. (2019c). The Homelessness Monitor: England 2019. London: Crisis.

Fitzpatrick, S., Watts, B., Pawson, H., Bramley, G., Wood, J., Stephens, M., \& Blenkinsopp, J. (2021a). The Homelessness Monitor: England 2021. London: Crisis.

Gaetz, S., \& Dej, E. (2017). A new direction: A framework for homelessness prevention. Toronto: Homeless Hub.

Glisson, G., \& Fischer, R. (2001). Serving the homeless: Evaluating the effectiveness of homeless shelter services. Journal of Sociology and Social Welfare, 28(4), 89-97.

Greer, A. L., Shinn, M., Kwon, J., \& Zuiderveen, S. (2016). Targeting services to individuals most likely to enter shelter: Evaluating the efficiency of homelessness prevention. Social Service Review, 90(1), 130-155. https://doi.org/10.1086/686466

Heise, A., \& Lierse, H. (2011). The effects of European Austerity Programmes on social security systems. Modern Economy, 2(4), 498513. https://doi.org/10.4236/me.2011.24055

Herman, D., Conover, S., Felix, A., Nakagawa, A., \& Mills, D. (2007). Critical Time

Intervention: An empirically supported model for preventing homelessness in high risk groups. The Journal of Primary

Prevention, 28(3-4), 295-312.

https://doi.org/10.1007/s10935-007-0099-3

Homelessness Action Group (2020). The framework of policies, approaches and plans needed to end homelessness in Wales (What ending homelessness in Wales looks like). Report from the Homelessness Action Group for the Welsh Government. Cardiff: Welsh Government.

Hignite, L. R., \& R. Haff, D. (2017). Rapid rehousing of formerly homeless jail and prison inmates. Housing, Care and Support, 20(4), 137-151. https://doi.org/10.1108 /HCS-06-2017-0015

Hudson, C. G., \& Vissing, Y. M. (2010). The geography of adult homelessness in the US: Validation of state and county estimates. Health \& Place, 16(5), 828-837. https://doi.org/10.1016/j.healthplace.2010. 04.008

Jackson, R. (2018). Trapped on the streets understanding rough sleeping in Wales. Swansea: Shelter Cymru.

Johnsen, S., \& Watts, B. (2014). Homelessness and poverty: Reviewing the links. Edinburgh: Heriot-Watt University.

Johnson, G., \& Mendes, P. (2014). Taking control and 'Moving On': How young people turn around problematic transitions from out-ofhome care. Social Work and Society, 12(1), 115.

Johnson, G., Scutella, R., Tseng, Y.-P., \& Wood, G. (2019). How do housing and labour markets affect individual homelessness? Housing Studies, 34(7), 1089-1116. https://doi.org/10.1080/02673037.2018.152 0819

Jones, A., Bretherton, J., Bowles, R., \& Croucher, K. (2010). The effectiveness of schemes to enable households at risk of domestic violence to remain in their homes. London: Department for Communities and Local Government.

Kasprow, W. J., \& Rosenheck, R. A. (2007). Outcomes of critical time intervention case management of homeless veterans after psychiatric hospitalization. Psychiatric Services, 58(7), 929-935. https://doi.org/10.1176/ps.2007.58.7.929

Keenan, C., Miller, S., Hanratty, J., Pigott, T., Hamilton, J., Coughlan, C., Mackie, P., Fitzpatrick, S., \& Cowman, J. (2021). Accommodation-based interventions for 
individuals experiencing, or at risk of experiencing, homelessness. Campbell Systematic Review, 17(2).

https://doi.org/10.1002/cl2.1165

Kelly, P. (2020). Risk and protective factors contributing to homelessness among foster care youth: An analysis of the National Youth in Transition Database. Children and Youth Services Review, 108, 1-8.

https:/ / doi.org/10.1016/j.childyouth.2019.1 04589

Kenna, P., Busch-Geertsema, V., Benjaminsen, L., \& Nasarre-Aznar, S. (2016). Pilot projectpromoting protection of the right to housinghomelessness prevention in the context of evictions. Final report. Publications Office of the European Union.

Kertesz, S. G., \& Johnson, G. (2017). Housing First: Lessons from the United States and challenges for Australia. Australian Economic Review, 50(2), 220-228. https://doi.org/10.1111/1467-8462.12217

Kube, A., Das, S., \& Fowler, P. J. (2019). Allocating interventions based on predicted outcomes: A case study on homelessness services. Proceedings of the AAAI Conference on Artificial Intelligence, 33(01), 622-629. https://doi.org/10.1609/aaai.v33i01.330162 2

Lewer, D., Braithwaite, I., Bullock, M., Eyre, M. T., White, P. J., Aldridge, R. W., Story, A., \& Hayward, A. C. (2020). COVID-19 among people experiencing homelessness in England: a modelling study. The Lancet Respiratory Medicine, 8(12), 1181-1191. https:/ / doi.org/10.1016/S22132600(20)30396-9

Lutze, F. E., Rosky, J. W., \& Hamilton, Z. K. (2014). Homelessness and reentry: A multisite outcome evaluation of Washington State's reentry housing program for high risk offenders. Criminal Justice and Behavior, 41(4), 471-491. https://doi.org/10.1177/ 0093854813510164

MacKenzie, D. (2018). The Geelong Project: Interim report 2016-2017. Geelong: Barwon Child, Youth and Family.

Mackie, P., Johnsen, S., \& Wood, J. (2017). Ending rough sleeping: What works? An international evidence review. London: Crisis.

Mackie, P. K. (2015). Homelessness prevention and the Welsh Legal Duty: Lessons for international policies. Housing Studies, 30(1), 40-59. https://doi.org/10.1080/ 02673037.2014.927055

Maher, C., \& Allen, M. (2017). What is preventing us from preventing homelessness? A review of the Irish national preventative strategy. European Journal of Homelessness, 8(2), 119135.

McMordie, L. (2020). Avoidance strategies: Stress, appraisal and coping in hostel accommodation. Housing Studies, 36(3), 380396. https://doi.org/10.1080/02673037. 2020.1769036

Ministry of Housing, Communities and Local Government (2018). The rough sleeping strategy. London: MHCLG.

Ministry of Housing, Communities and Local Government (2019). Rough sleeping initiative 2018: Impact evaluation. London: MHCLG.

Ministry of Housing, Communities and Local Government (2020). Coronavirus (COVID-19) emergency accommodation survey data: May 2020. London: MHCLG.

Montgomery, A. E., Metraux, S., \& Culhane, D. (2013). Rethinking homelessness prevention among persons with serious mental illness. Social Issues and Policy Review, 7(1), 58-82. https:// doi.org/10.1111/j.17512409.2012.01043.x

Mosites, E., Parker, E. M., Clarke, K. E. N., Gaeta, J. M., Baggett, T. P., Imbert, E., Sankaran, M., Scarborough, A., Huster, K., Hanson, M., Gonzales, E., Rauch, J., Page, L., McMichael, T. M., Keating, R., Marx, G. E., Andrews, T., Schmit, K., Morris, S. B., Dowling, NF., Peacock, G., Buff, A., Jamison, C., Marcus, R., Rao, CY., Self, JL., Tobolowsky, F., Williams, S., Kay, M., Bobba, N., Cohen, S., Fuchs, J., Nguyen, T., \& Stoltey, J. (2020). Assessment of SARS-CoV-2 infection prevalence in homeless shelters - Four U.S. Cities, March 27-April 15, 2020. MMWR. Morbidity and Mortality Weekly Report, 69(17), 521-522. https://doi.org/10.15585/mmwr.mm6917e 1

O'Donnell, J. (2019). Does social housing reduce homelessness? A multistate analysis of housing and homelessness pathways. Housing Studies, 1-27. https://doi.org/10.1080/02673037.2018.154 9318 
O'Flaherty, B. (2004). Wrong person and wrong place: For homelessness, the conjunction is what matters. Journal of Housing Economics, 13(1), 1-15. https:// doi.org/ 10.1016/j.jhe.2003.12.001

Olsson, L., \& Nordfeldt, M. (2008). Homelessness and the tertiary welfare system in Swedenthe role of welfare state and non-profit sector. European Journal of Homelessness, 2, 33-44.

O'Sullivan, E. (2020). Reimagining homelessness for policy and practice. Bristol: The Policy Press.

Parsell, C., Clarke, A., \& Kuskoff, E. (2020). Understanding responses to homelessness during COVID-19: An examination of Australia. Housing Studies, 1-14. https:// doi.org/10.1080/02673037.2020.182 9564

Parsell, C., \& Fitzpatrick, S. (2016) Breaking the cycle of violence, Policy Forum, https://www.policyforum.net/breakingcycle-violence/

Parsell, C, \& Marston, G. (2012). Beyond the 'at risk' individual: Housing and the eradication of poverty to prevent homelessness. Australian Journal of Public Administration, 71(1), 33-44. https://doi.org/10.1111/j.14678500.2012.00758.x

Pearson, C., Montgomery, A. E., \& Locke, G. (2009). Housing stability among homeless individuals with serious mental illness participating in Housing First programs. Journal of Community Psychology, 37(3), 404417. https://doi.org/10.1002/jcop.20303

Piña, G., \& Pirog, M. (2019). The impact of homeless prevention on residential instability: evidence from the homelessness prevention and rapid re-housing program. Housing Policy Debate, 29(4), 501-521. https://doi.org/10.1080/10511482.2018.153 2448

Pleace, N. (2019). Preventing homelessness: A review of the international evidence. Research report. Dublin: Simon Communities of Ireland.

Pleace, N., Knutagård, M., Culhane, D., \& Granfelt, R. (2016). The strategic response to homelessness in Finland: Exploring innovation and coordination within a national plan to reduce and prevent homelessness. In N. Nichols \& C. Doberstein (Eds.), Exploring Effective Systems Responses to
Homelessness (pp. 426-442). Toronto: The Homeless Hub Press.

Quigley, J., Raphael, S., \& Smolensky, E. (2001). Homeless in America, homeless in California. The Review of Economics and Statistics, 83(1), 37-51. https://doi.org/10.1162/0034653017501600 27

Reid, B. (2021). Preventing homelessness in Scotland. Edinburgh: Crisis.

Roman, C. G., \& Travis, J. (2006). Where will I sleep tomorrow? Housing, homelessness, and the returning prisoner. Housing Policy Debate, 17(2), 389-418. https://doi.org/10.1080/10511482.2006.952 1574

Schwan, K., French, D., Gaetz, S., Ward, A., Akerman, J., \& Redman, M. (2018). Preventing youth homelessness: An international review of evidence. Cardiff: Wales Centre for Public Policy.

Scottish Parliament Equal Opportunities Committee. (2012). 4th Report, 2012 (Session 4): Having and keeping a home: Steps to preventing homelessness among young people.

Shinn, M., \& Cohen, R. (2019). Homelessness prevention: A review of the literature. Centre For Evidence-Based Solutions to Homelessness.

Shinn, M., Baumohl, J., \& Hopper, K. (2001). The Prevention of homelessness revisited. Analyses of Social Issues and Public Policy, 1(1), 95-127. https://doi.org/10.1111/15302415.00006

Shinn, M., Greer, A. L., Bainbridge, J., Kwon, J., \& Zuiderveen, S. (2013). Efficient targeting of homelessness prevention services for families. American Journal of Public Health, 103(S2), S324-S330. https://doi.org/10.2105/AJPH.2013.301468

Spencer, M. B., \& Jones-Walker, C. (2004). Interventions and services offered to former juvenile offenders re-entering their communities: An analysis of program effectiveness. Youth Violence and Juvenile Justice, 2(1), 88-97. https://doi.org/10.1177/1541204003260049

Spinney, A., \& Blandy, S. (2011). Homelessness prevention for women and children who have experienced domestic and family violence: Innovations in policy and practice. Melbourne: AHURI. 
St Basils (2015) Developing positive pathways to adulthood. Birmingham: St Basils.

Stephens, M., Fitzpatrick, S., Elsinga, M., Steen, G. V., \& Chzhen, Y. (2010). Study on housing exclusion: Welfare policies, labour market and housing provision. Brussels: European Commission.

Stirling, T. (2018). Youth homelessness and care leavers: Mapping interventions in Wales. Cardiff: Wales Centre for Public Policy.

Thomas, I., \& Mackie, P.K. (2020). The principles of an ideal homelessness administrative data system: lessons from global practice. European Journal of Homelessness, 14(3), 63-85.

Thunder, J., \& Rose, C. B. (2019). Local authority spending on homelessness: Understanding recent trends and their impact. London: St Mungo's and Homeless Link.

Todis, B., Bullis, M., Waintrup, M., Schultz, R., \& D'Ambrosio, R. (2001). Overcoming the odds: qualitative examination of resilience among formerly incarcerated adolescents. Exceptional Children, 68(1), 119-139. https://doi.org/10.1177/0014402901068001 07

Tsemberis, S. (2010). Housing First: The pathways model to end homelessness for people with mental illness and addiction manual. Minnesota: Hazelden Publishing.

Tually, S., Faulkner, D., Cutler, C., \& Slatter, M. (2008). Women, domestic and family violence and homelessness: A synthesis report. Melbourne: Flinders Institute for Housing, Urban and Regional Research.
Tutty, L. M., Ogden, C., Giurgiu, B., \& WeaverDunlop, G. (2013). I built my house of hope: Abused women and pathways into homelessness. Violence Against Women, 19(12), 1498-1517. https:// doi.org/10.1177/1077801213517514

Vizard, P., \& Hills, J. (2021). The Conservatives' record on social policy from May 2015 to preCOVID 2020: Policies, spending and outcomes. London: London School of Economics.

Watts, B., Bramley, G., Blenkinsopp, J., \& McIntyre, J. (2019). Homelessness prevention in Newcastle: Examining the role of the 'local state' in the context of austerity and welfare reforms. Edinburgh: Heriot-Watt University.

Watts, B., Johnsen, S., \& Sosenko, F. (2015). Youth homelessness in the UK. London: OVO Foundation.

Watts, B., Littlewood, M., Blenkinsopp, J., \& Jackson, F. (2018). Temporary accommodation in Scotland: Final report. Edinburgh: Social Bite.

Wilding, M. (2020). The challenges of measuring homelessness among armed forces veterans: service provider experiences in England. European Journal of Homelessness, 14(1), 107122.

Woodhall-Melnik, J. R., \& Dunn, J. R. (2016). A systematic review of outcomes associated with participation in Housing First programs. Housing Studies, 31(3), 287-304. https://doi.org/10.1080/02673037.2015.108 0816 